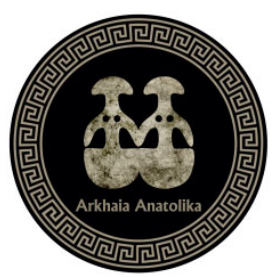

Arkhaia Anatolika

Anadolu Arkeolojisi Araştırmaları Dergisi

The Journal of Anatolian Archaeological Studies

Volume 4 (2021)

\title{
Tisna Antik Kentinde Bulunan Lydia Seramikleri Üzerine İlk Düşünceler
}

Preliminary Thoughts on Lydian Pottery Found at Tisna

Aydin ERÖN

(iDhttps://orcid.org/0000-0003-1611-2296
Merve Sultan ÇAKAN

(iD https:/ / orcid.org/0000-0002-3366-7165

Geliş Tarihi: 14.12.2020 | Kabul Tarihi: 05.01.2021 | Online Yayın Tarihi: 09.01.2021

Makale Künyesi: Erön, A. ve Çakan, M. S. (2021). Tisna Antik Kentinde Bulunan Lydia Seramikleri Üzerine İlk Düşünceler. Arkhaia Anatolika, 4, 1-14. DOI: 10.32949/Arkhaia.2021.24
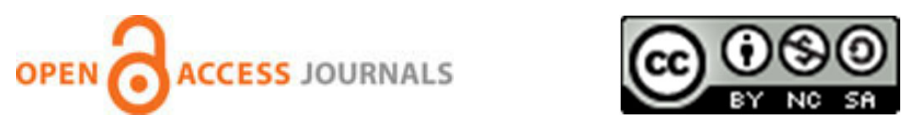

Arkhaia Anatolika, Anadolu Arkeolojisi Araştırmaları Dergisi "Açık Erişimli" (Open Access) bir dergidir. Kullanıcılar, dergide yayınlanan makalelerin tamamin tam metin olarak okuyabilir, indirebilir, makalelerin çıktısını alabilir ve kaynak göstermek suretiyle bilimsel çalışmalarında bu makalelerden faydalanabilir. Bunun için yayıncıdan ve yazar(lar)dan izin almasına gerek yoktur.

Dergide yayınlanan makalelerin bilimsel ve hukuki sorumluluğu tamamen yazar(lar)ına aittir.

Arkhaia Anatolika, The Journal of Anatolian Archaeological Studies follows Open Access as a publishing model. This model provides immediate, worldwide, barrier-free access to the full text of research articles without requiring a subscription to the articles published in this journal. Published material is freely available to all interested online readers.

The scientific and legal propriety of the articles published in the journal belongs exclusively to the author(s). 


\title{
Tisna Antik Kentinde Bulunan Lydia Seramikleri Üzerine İlk Düşünceler Preliminary Thoughts on Lydian Pottery Found at Tisna
}

Aydın ERÖN* Merve Sultan ÇAKAN ${ }^{* *}$

\section{Öz}

Antik Dönem'de Aiolis Bölgesi'nde yer alan Tisna antik kenti günümüzde İzmir ili, Aliağa ilçe sınırları içerisinde kalmaktadır. Tisna antik kentinde 2018 ve 2019 yıllarında gerçekleştirilen yüzey araştırmalarında ağırlıklı olarak Sarıkale Tepe ve Kocakale Tepe mevkiileri incelenmiştir. Bu çalışmalarda yedi adet Lydia seramiği parçası saptanmıştır. Bu parçalardan beş tanesi Sarıkale Tepe mevkiinde, iki tanesi ise Kocakale Tepe mevkiinde bulunmuştur. Sarıkale Tepe buluntularının kutsal alan olduğu düşünülen bir bölgeden gelmesi önemlidir. Kocakale Tepe mevkii örnekleri ise nekropolis olabileceği düşünülen bir alanda bulunmuştur. Çalışmada ele alınan Lydia seramiklerinin tamamı "damarlı boyama" tekniğinde boyanmış olup, bunlar parlak ve mat boyalı olmak üzere iki farklı stildedir. Tisna buluntusu Lidya seramikleri, oinokhoe, tabak, skyphos ve çanak gibi farklı formlara ait parçalardan oluşmaktadır.

Tisna antik kenti Lydia Bölgesi'ne bağlanan bir yol ağının yakınında kurulmuştur. Bu nedenle yerleşimin Lydia kültürü ile etkileşim içerisinde olduğu düşüncesi üzerinde durulmaktadır. Kentte gerçekleştirilen yüzey araştırmaları sırasında bulunan Lydia seramikleri de bu etkiyi kanıtlamaktadır. Lydia Krallığı'nın özellikle MÖ 7.-6. yüzyıllar arasında Batı Anadolu coğrafyası üzerinde hakimiyet kurduğu bilinmektedir. Lydia seramikleri de söz konusu dönemde geniş bir coğrafyada karşımıza çıkmaktadır. Bu çalışmada ele alınan Lydia "damarlı boyama" tekniğinde yapılmış seramik parçaları, benzer örnekler ve yerleşimdeki diğer buluntular yardımıyla MÖ Geç 7.-Erken 6. yüzyıllar arasına tarihlendirilmiştir.

Anahtar Kelimeler: Tisna, Aiolis, Lydia, Lydia seramiği, Arkaik seramik

\begin{abstract}
The ancient city of Tisna, which was located in the Aiolis Region in the Ancient Period, is today within the borders of Aliağa district in İzmir. During the survey in 2018 and 2019, Sarikale Tepe and Kocakale Tepe were mainly studied. In these studies, seven pieces of Lydian pottery were found. Five of them came from Sarıkale Tepe and two from Kocakale Tepe. It is also important that the Sarıkale Tepe finds come from an area considered to be a sacred area. Kocakale Tepe samples were found in an area thought to be a necropolis. All of the Lydia pottery discussed in this study decorated with "streaky glaze", and they are in two different styles, glossy and matte. Lydian pottery found at Tisna consists of different forms such as oinochoe, dish, skyphos and bowl.

The ancient city of Tisna was established near a road network to Lydia Region. Therefore, it is thought that the settlement interacts with the Lydian culture. Pottery found during the survey in the ancient city also

\footnotetext{
* Doç. Dr. Aydın Erön, Aydın Adnan Menderes Üniversitesi, Fen-Edebiyat Fakültesi, Arkeoloji Bölümü, Aydın/TR. E-mail: aeron@adu.edu.tr / Orcid iD: 0000-0003-1611-2296

** Arkeolog Merve Sultan Çakan, Aydın Adnan Menderes Üniversitesi, Sosyal Bilimler Enstitüsü, Doktora Öğrencisi, Aydın/TR. E-mail:mervesultancakan@gmail.com / Orcid iD: 0000-0002-3366-7165
} 
proves this cultural interaction. It is known that the Lydian Kingdom dominated Western Anatolia, especially between $7^{\text {th }}$ and $6^{\text {th }}$ centuries BC. Lydian pottery also appears in a wide area in this period. The pottery decorated with "streaky glaze" from Tisna was dated to the late 7th-early $6^{\text {th }}$ centuries BC with the help of similar samples and other finds from the settlement.

Keywords: Tisna, Aeolis, Lydia, Lydian pottery, Archaic pottery

\section{Giriş}

Antik Dönem'de Aiolis Bölgesi'nde yer alan Tisna antik kenti günümüzde İzmir ili, Aliağa ilçesi sınırları ${ }^{1}$ içerisinde kalmaktadır (fig. 1). Aiolis Bölgesi'ndeki diğer antik kentlerin konumları incelendiğinde, yerleşim alanlarının genel karakterleri itibariyle ikiye ayrıldığı sonucuna ulaşılabilir. Myrina ve Kyme gibi kıyıda yer alan kentlerin yanında, iç bölgelerle bağlantılı olarak değerlendirebileceğimiz Tisna gibi yerleşimler de mevcuttur. Söz konusu sebeple Tisna antik kentinin kurulduğu coğrafyayı dikkatli incelemek gerekir. Yerleşim alanı Aspordene (Yunt) ve Sardene (Dumanlı) dağları arasında konumlanmıştır. Kentin mevcut kalıntıları $179 \mathrm{~m}$ yüksekliğindeki Sarıkale Tepe ile $357 \mathrm{~m}$ yüksekliğindeki Kocakale Tepe mevkii olarak adlandırilan alanlar üzerinde bulunmaktadır. Yapilan inceleme ve araştırmalar sonucunda kentin etrafının su kaynakları ile çevrili olduğu saptanmıştır. Yerleşimin kuzeyinden geçen ve günümüzde GüzelhisarKocaçay olarak adlandırılan su kaynağının, kentin yer seçiminde oldukça önemli olduğu anlaşılmaktadır. Söz konusu su kaynağının Antik Dönem'de Pythikos veya Titanus olarak adlandırıldığı düşünülmektedir. Tisna isminin de bu su kaynağından geldiği fikri üzerinde durulmaktadır².

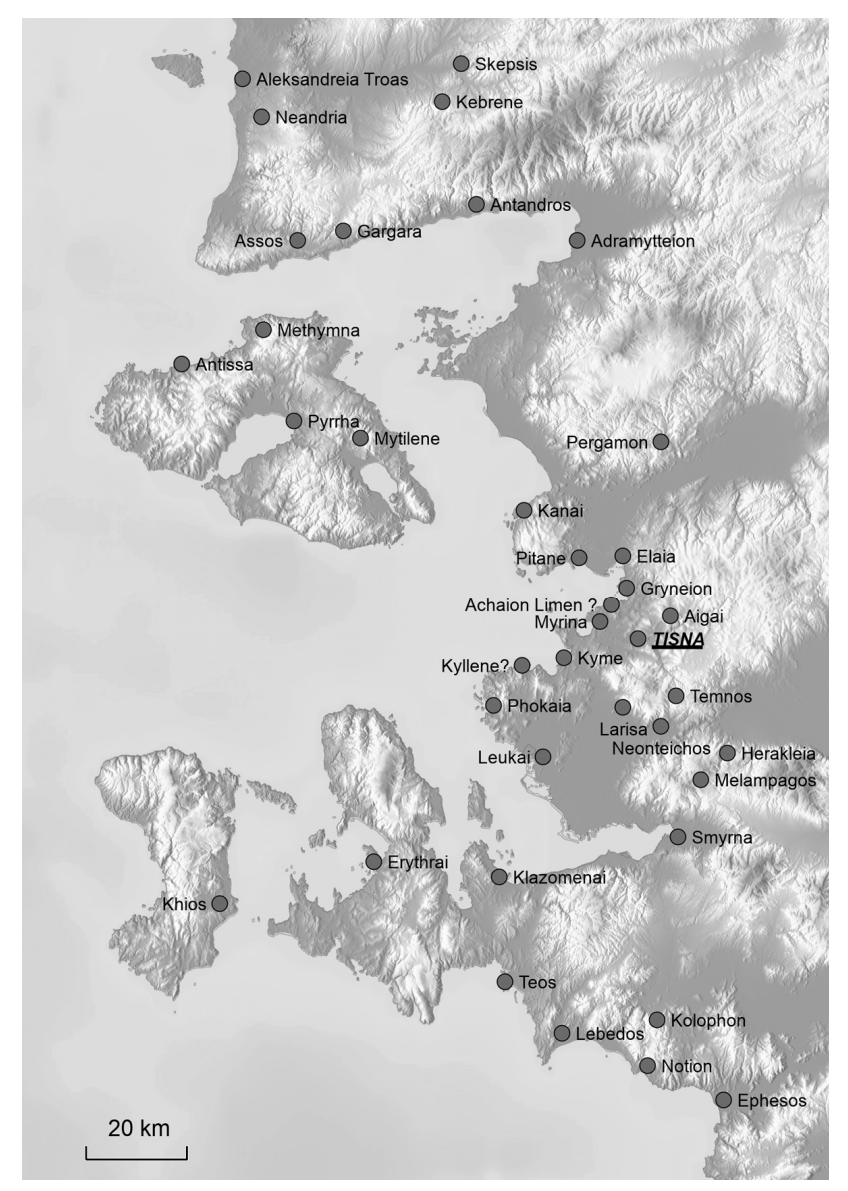

Figür 1: Tisna antik kenti ve yakın çevresini gösteren harita

Kentin konumu incelendiğinde, Aiolis ile Lydia bölgeleri arasındaki ulaşımı sağlayan bir yolun hemen yakınında kurulduğu anlaşılmaktadır³. Tisna her ne kadar Aiolis Bölgesi sınırları içerisinde kalsa da araştırmalar sırasında bulunan Lydia seramikleri, doğusunda yer alan Lydia Bölgesi ile etkileşim içerisinde olduğunu kanıtlar niteliktedir4

\footnotetext{
1 Yerleşim günümüzde Aliağa ilçesinin doğusunda yer alan Uzunhasanlar, Güzelhisar, Karakuzu ve Karaköy mahalleleri sınırları içerisinde kalmaktadır.

2 Erdan 2020a, 4. Kentin isminin Nehir Tanrısı Titanios'tan geldiği düşünülmektedir.

3 Uzunhasanlar ve Avdal mahalleri arasında kalan söz konusu yol hattı günümüzde de kullanılmaya devam etmektedir.

4 Aioller'in, Erken Demir Çağı'nın başlarından beri Lydialılar'ın batı komşusu olduğu bilinmektedir. Alyattes'in Kimmer istilasını sonlandırmasının ardından Lydia egemenliği Aiolis Bölgesi'nin yer aldığı batı kıyıları da dahil
} 
Aiolis Bölgesi'nde yer alan diğer antik kentlerle kıyaslandığında, Tisna hakkındaki bilgilerimiz ne yazık ki çok daha azdır. Kent hakkındaki en erken bilgiler Yaşlı Plinius'un "Naturalis Historia" adlı eserinde karşımıza çıkar (Plin. nat. V, 30). Yaşlı Plinius söz konusu eserinde Tisna antik kentinden Titanus Irmağı yakınında yer alan Titanus kenti olarak bahseder. 19. yüzyıla kadar yerleşimin üzerinde çok durulmadığı anlaşılmaktadır. Söz konusu tarihten sonra A. H. Sayce ${ }^{5}$, M. Guichon ${ }^{6}$, C. Schuchhardt 7 , W. von Diest ${ }^{8}$, M. Baltazzi $^{9}$, A. Conze ${ }^{10}$ ve E. Doğer ${ }^{11}$ gibi gezgin ve araştırmacıların Tisna ile ilgili yaptıkları çalışmalar bulunmaktadır. Tisna antik kentindeki son sistemli yüzey araştırması çalışmaları 2018 yılından itibaren E. Erdan başkanlığındaki bir ekip tarafından yürütülmektedir ${ }^{12}$. Makale konusunu oluşturan Lydia seramik örnekleri de söz konusu bu çalışmalar sırasında bulunmuştur ${ }^{13}$.

\section{Lydia Seramikleri}

Tisna antik kentinde bulunan eserleri incelemeden önce Lydia seramikleri hakkında kısa bir bilgi vermek yararlı olacaktır. Lydia seramikleri Batı Anadolu coğrafyasının önemli yerel seramik gruplarından bir tanesidir. Söz konusu seramik kültürü, Lydia Krallı̆̆ı'nın egemenlik sahası içerisinde kalan alanlarda, MÖ 9.-6. yüzyıllar arasında karşımıza çıkmaktadır. Lydia seramiklerinin anlaşılmasında Sardeis ${ }^{14}$ buluntuları oldukça önemlidir. Kentte gerçekleştirilen kazı çalışmaları sırasında ortaya çıkarılan eserler ışığında özellikle İç ve Batı Anadolu coğrafyasında yer alan antik kentlerde bulunan Lydia seramikleri de yorumlanmaya başlanmıştır. Lydia seramikleri Sardeis dışında Ephesos ${ }^{15}$, Smyrna16, Daskyleion ${ }^{17}$, Gordion ${ }^{18}$, Miletos ${ }^{19}$, Aphrodisias ${ }^{20}$, Larisa ${ }^{21}$, Thyateira ${ }^{22}$, Pitane ${ }^{23}$, Aigai ${ }^{24}$ ve Börükçü 25 gibi önemli yerleşimlerde karşımıza çıkmaktadır. R. G. Gürtekin-Demir, Lydia seramiklerini "Sardeis buluntuları", "Sardeis yakın çevresi buluntuları", "bir süre Lydia egemenliği altında kalan bölgelerdeki örnekler" ve "Lydia egemenliği altında olmayan yerleşimlere ticaret yoluyla giden seramikler" başlıkları altında değerlendirmiştir ${ }^{26}$. Lydia seramiklerinin üzerinde görülen bezeme tekniklerinden yola çıkan araştırmacılar genellikle

\footnotetext{
olmak üzere her yöne doğru hızla genişlemiştir (Kerschner 2010, 247, 249). Ayrica Alyattes'in oğlu Kroisos'un Ionia ve Aiolis'i tamamıyla egemenliği altına aldığı bilinmektedir (Hdt. I, 26).

5 Sayce 1882, 221-222.

6 Reinach 1885, 73-75.

7 Schuchhardt 1887, 1213.

8 von Diest 1889, 32-33.

9 Reinach 1891, 20-22.

10 Conze 1910, 1-8.

11 Doğer 2017, 79.

12 Erdan 2019, 91-111; Erdan 2020a; Erdan 2020b, 353-371.

13 Tisna antik kenti buluntusu Lydia seramiklerini çalışmamız konusunda her türlü yardım ve desteği sağlayan Doç. Dr. Emre Erdan ve Tisna araştırma ekibine teşekkürü bir borç biliriz. Yayında kullanılan harita, fotoğraf ve çizimler Tisna yüzey araştırması arşivinden alınmıştır.

14 Greenewalt 1966; Greenewalt 2010, 107-124; Gürtekin 1998.

15 Kerschner 2007, 232-235; Kerschner 2008, 335-336.

16 Akurgal 1950, 38-39; Cook 1958/1959, 31.

17 Gürtekin-Demir 2002, 111-143; Koçak-Yaldır 2009, 86-109.

18 Schaus 1992, 151.

19 Panteleon ve Senff 2008, 33.

${ }^{20}$ Mierse 1986, 413-424.

${ }^{21}$ Boehlau ve Schefold 1942, lev. 24, no. 3; Greenewalt 1966, 152, 154.

22 Akdeniz ve Erön 2017, 79-92; Çakan 2018.

${ }^{23}$ Greenewalt 1966, 150, 152, 159, 208.

24 Özver 2012, 10.

25 Gider-Büyüközer 2014, 115-116, 122-123.

26 Gürtekin 1998, 9-13; Gürtekin-Demir 2007, 47.
} 
söz konusu grubu "kırmızı üzerine siyah", "bikrom", “damarlı boyama" ve "mermer taklidi" örnekler başlıkları altında incelemişlerdir.

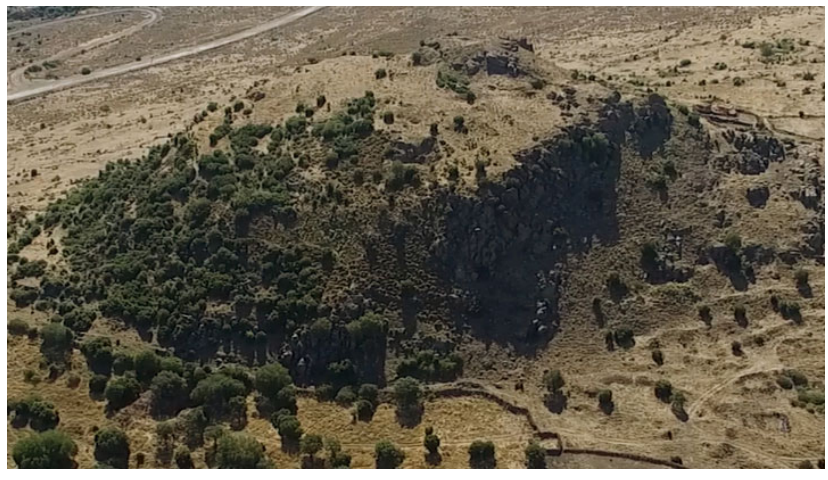

Figür 2: Sarıkale Tepe akropolü ve batı yamacının genel görünüşü

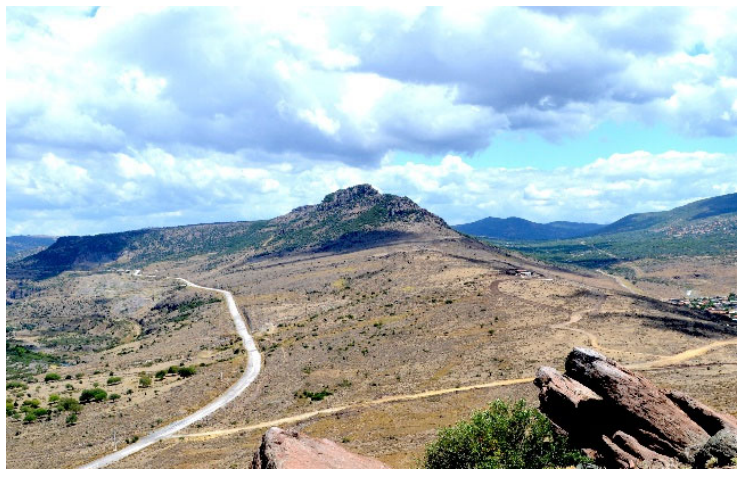

Figür 3: Kocakale Tepe mevkiinin genel görünüşü

\section{Tisna Buluntusu Lydia Seramikleri}

Tisna antik kenti 2018 ve 2019 yılı yüzey araştırmaları ağırlıklı olarak Sarıkale Tepe (fig. 2) ve Kocakale Tepe (fig. 3) mevkiilerinde gerçekleştirilmiştir ${ }^{27}$. Söz konusu alanlarda yapılan incelemeler sırasında bulunan Lydia seramik örneklerinden "damarlı boyama" tekniğinde yapıldığı net olarak anlaşılan 7 tanesi çalışma içerisinde incelenmiştir. Seramik parçalarından 5 tanesi Sarıkale Tepe, 2 tanesi ise Kocakale Tepe'de bulunmuştur (fig. 4). Sarıkale Tepe örneklerinin kutsal alan olduğu düşünülen bir mevkide bulunması önemlidir28. Ayrıca söz konusu tepenin batı yamacında da Lydia seramiklerine rastlanmıştır. Kocakale Tepe mevkii örnekleri ise nekropolis olabileceği düşünülen bir alanda, arazinin kuzeyinde bulunmuştur29.

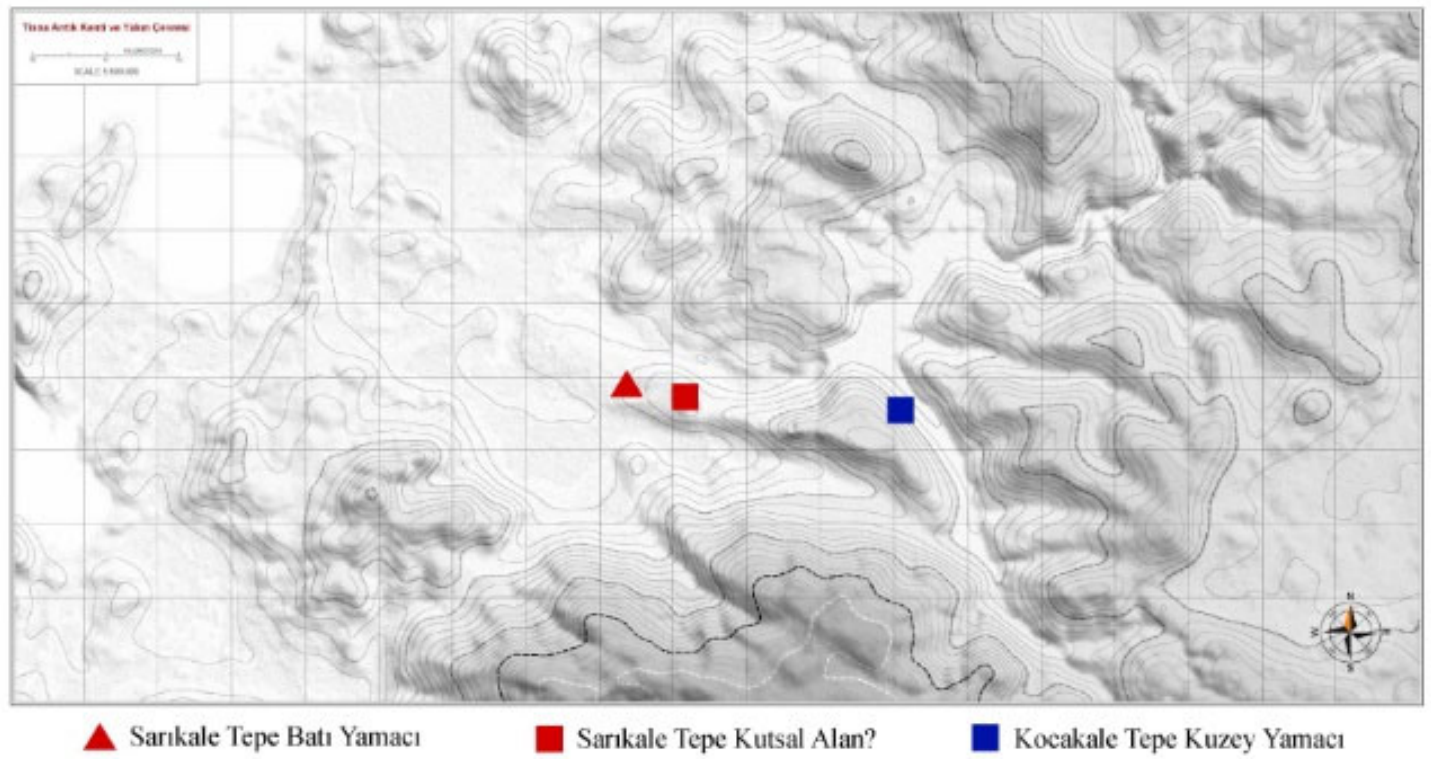

Figür 4: Tisna buluntusu “Damarlı Boyama” seramiklerinin buluntu yerlerini gösteren harita

27 Erdan et al. 2019, 459-470.

28 Yüzey araştırması ekibi kutsal alan buluntusu seramiklerin adak amaçlı kullanılmış olabileceklerini düşünmektedir.

29 Erdan 2020a, 21-22. Kocakale Tepe mevkinin kuzeyindeki teraslı alanların nekropolis alanı oluşturmak için tasarlandıkları düşünülmektedir. Aiolis Bölgesi'ndeki diğer nekropolis alanları incelendiğinde, bazılarında teraslama yapıldığı bilinmektedir. Sardene (Dumanlı) Dağı'nın güneyindeki yerleşimlerde söz konusu teraslama uygulamasıyla karşılaşılmaktadır. 
Sarıkale Tepe ve Kocakale Tepe buluntusu Lydia seramiklerinin hamur renkleri kırmızı, kahverengi ve sarı tonları arasında değişkenlik göstermektedir. Hamurlarında kum, mika, kireç ve yer yer taşçı katkısı tespit edilmiştir. Bezemeler genel olarak kahverengi ve kırmızının farklı tonlarındadır. Tisna buluntusu Lydia seramiklerinin "damarlı boyama" tekniğinde yapıldığı anlaşılmaktadır. TIS.19.SK S-96 ve TISS.19.SK S-55 envanter numaralı parçalar üzerinde "damarlı boyama" tekniğinin yanında "kırmızı bikrom30" tekniğinin de uygulanmış olma ihtimali vardır. Fakat söz konusu seramikler çok küçük parçalar halinde bulundukları için "kırmızı bikrom" tekniğinin kullanımında kuşkular bulunmaktadır. Bu nedenle parçaların sadece "damarlı boyama" başlığı altında incelenmesine karar verilmiştir. Tisna' da "kırmızı üzerine siyah" 31 ve "mermer taklidi32" tekniğinde yapılmış Lydia seramik örneklerine ise henüz rastlanmamıştır.

\section{Damarlı Boyama (Streaky Glaze)}

"Damarlı boyama", Lydia seramiğinin en kolay ve basit tekniklerinden bir tanesidir. Söz konusu teknikte kabın yüzeyine demir oksit içerikli bir boya sürülmektedir. Fırça üzerindeki kil miktarına bağlı olarak fırınlama aşamasından sonra seramiklerin yüzeyinde kırmızı, kahverengi ve morumsu siyah tonları arasında değişen renkler ortaya çıkmaktadır. Fırçanın kap yüzeyinde yatay olarak hareket ettirilmesi ile damarlı ve metalik bir görünüm elde edilmektedir. Vazo üzerinde damarlı görünümün uygulandığ1 alanlar dışında kalan rezerv kısımlara bazen ek renk (beyaz, morumsu kırmızı) kullanılarak basit bezemeler

\footnotetext{
30 "Bikrom" teknik, genel olarak zemin rengi haricinde iki renk kullanılarak yapılan bezemeleri ifade etmek için kullanılmıştır. Söz konusu teknikte en çok kırmızı, siyah ve beyaz renklerin tercih edildiği bilinmektedir. Kullanılan renk yoğunluğuna ve baskın zemin rengine göre "beyaz bikrom" ve "kırmızı bikrom" olarak iki alt gruba ayrılmaktadır. Her iki teknikte de zemin beyaz astarla kaplanmakta ya da astar kullanılmadan perdahlı yüzeye bezemeler uygulanmaktadır. Kırmızı renk geçiş bantlarında ve bezeme kuşaklarında; siyah renk ise motiflerin yapılmasında ve yatay geçiş çizgilerinde tercih edilmektedir. "Kırmızı bikrom” tekniğinin MÖ 7.-6. yüzyıllar arasında kullanıldığı bilinmektedir (Gürtekin 1998, 122). Söz konusu bezeme stilinde askı konsantrik yarım daireler, yatay dalgalı çizgi bezemeleri, konsantrik daireler, yarım daireler ve farklı kalınlıklarda bant bezemeler yaygin olarak kullanım görmüştür. Anadolu' da Sardeis (Greenewalt 2010, 110, fig. 10; Gürtekin 1998, 110-111), Daskyleion (Gürtekin-Demir 2002, 121, fig. 10; Koçak-Yaldır 2009, 90-91) ve Thyateira (Akdeniz ve Erön 2017, 85-87, fig. 6-8, çiz. 3-5; Çakan 2018, 46-47) yerleşimlerinde “kırmızı bikrom” tekniğinde yapılmış Lydia seramik örnekleri tespit edilmiştir.

31 "Kırmızı üzerine siyah" seramikler Sardeis verileri ışığında Lydia seramiklerinin en erken grubunu temsil etmektedir. Yapılan araştırmalar sonucunda tekniğin MÖ 9.-6. yüzyıllar arasında kullanıldığı düşünülmektedir (Gürtekin 1998, 40). Anadolu' da Sardeis (Greenewalt 2010, 109-110, fig. 8-9; Gürtekin 1998, 25-26; Gürtekin-Demir 2011, 361-370), Ephesos (Brein 1978, 726-728, lev. 224-226; Kerschner 2007, 232-234, lev. 33.3,5; Kerschner 2008, 335-336, fig. 2, kat. no. 289-290; Kerschner 2010, 254, fig. 3), Smyrna (Mellaart 1955, 119, 122; Gürtekin 1998, 46; Gürtekin-Demir 2011, 360), Aphrodisias (Mierse 1986, 419), Gordion (Sams 1979, 13; Schaus 1992, 152-168) ve Thyateira (Akdeniz ve Erön 2017, 84-85, fig. 4, çiz. 1; Çakan 2018, 39-44) yerleşimlerinde yapılan kazı çalışmalarında "kırmızı üzerine siyah" teknikte yapılmış seramik örnekleri bulunmuştur. Ayrıca Afyonkarahisar ilinde gerçekleştirilen yüzey araştırması sırasında bulunan örnekler de anılmaya değerdir (Kızıltepe-Bilgin 2018, 71-74). Söz konusu teknikte genel olarak parlak kırmızı zemin üzerine mat siyah bezemeler kullanılmıştır. Kırmızı zemin bazen vazonun bütün yüzeyini kaplayacak şekilde astarla oluşturulurken bazen hamur renginde bırakılmıştır. Ancak her iki durumda da zemin çoğunlukla perdahlıdır. MÖ 7. yüzyılın ikinci yarısından itibaren seramiklerin bir kısmında kullanılan ek beyaz boya dikkat çekicidir.

32 "Mermer taklidi" seramikler, Lydia seramikleri arasında en fazla yayılım gösteren boyama tekniği olarak karşımıza çıkmaktadır. Söz konusu tekniğin düzenlenişi genel hatlarıyla "damarlı boyama" örneklerini hatırlatmaktadır. Beyaz astarlı veya astarsız zemin üzerinde demir oksit içerikli sulandırılmış boyanın dalgalı çizgiler oluşturacak şekilde sürülmesiyle elde edildiği bilinmektedir. Dalgalı çizgiler ve bukleler çok karakteristiktir. Boyanın sulandırılması ile farklı kalınlıklarda koyu turuncu ve kahverengi, soluk sarı aralığı, kırmızı veya kahverengi renk tonlarında bezemeler elde edilmektedir. Dalgalı çizgiler genel olarak düzensiz hatlara sahiptir. Bezeme için bir ya da birden fazla fırçanın kullanıldığı anlaşılmaktadır. "Mermer taklidi" seramikler genel olarak MÖ Geç 7. yüzyıl ile 5. yüzyılın ikinci yarısı arasına tarihlendirilmiştir. Tarih önerisi için bk; Greenewalt 1966, 144-151.
} 
(noktalar, nokta rozetler, dil motifi ve dar bantlar) yapıldığı bilinmektedir ${ }^{33}$. "Damarlı boyama" tekniği skyphos, krater ve oinokhoe formları üzerinde yaygın olarak karşımıza çıkar ${ }^{34}$. Söz konusu tekniğin tek başına tercih edildiği örneklerin yanı sıra farklı boyama teknikleri ile birlikte kullanıldığı örnekler de bulunmaktadır ${ }^{35}$.

Tisna buluntusu "damarlı boyama" tekniğinde yapılmış olan seramiklerde oinokhoe, tabak, skyphos ve çanak formlarının tercih edildiği anlaşılmaktadır (fig. 5-6). TİS 18.133 numaralı kaide parçasının oinokhoe formuna ait olduğu düşünülmektedir. "Damarlı boyama" tekniğinde yapılmış oinokhoe örnekleri Sardeis ${ }^{36}$ ve Thyateira ${ }^{37}$ yerleşimlerinde karşımıza çıkar. TİS 18.42 ve TİS 19.SK S-147 envanter numaralı seramikler ise tabak parçalarıdır. Thyateira ${ }^{38}$ yerleşiminde "damarlı boyama" tekniğinde yapılmış çok sayıda tabak parçası bulunmuştur. TİS 19.SK S-36 envanter numaralı eser bir skyphos parçasıdır. "Damarlı boyama" tekniğinin skyphoslar üzerinde yoğun olarak tercih edildiği bilinmektedir. Sardeis ${ }^{39}$, Daskyleion ${ }^{40}$, Thyateira ${ }^{41}$, Aigai42 ve Börükçü̈43' de benzer bezeme anlayışıyla yapılmış skyphos örnekleri bulunmaktadır. TISS 19.SK S-96 envanter numaralı parçanın skyphos krater formuna ait olabileceği düşünülmektedir. Aigai antik kentinde damarlı boyama tekniğinde süslenmiş bir adet skyphos krater parçası bulunmuştur ${ }^{44}$. Skyphos kraterler Lydia seramiğinin sevilen formları arasında yer almaktadır ${ }^{45}$. TİS 19.SK S55 envanter numaralı eser ise bir çanak parçasının ağız kısmı olmalıdır. Thyateira antik kentinde "damarlı boyama" tekniğinde yapılmış çanak örnekleri bulunmaktadır46. Ayrıca Sardeis antik kentinde $\mathrm{HoB}$ sektöründe bulunan bir çanak parçasının dikine tutamak detayı Tisna örneğini hatırlatmaktadır ${ }^{47}$.

Tisna buluntusu parçalarda "damarlı boyama" tekniği kap yüzeyinin tamamında ya da rezerv boşluklar bırakılacak şekilde yatay kalın bantlar halinde uygulanmıştır. Tís 18.42, TIS 18.172 ve TIS 19.SK S-36 envanter numaralı parçaların üzerindeki "damarlı boyama" tekniğinin metalik bir görüntüde parlak yapıldığı anlaşılmaktadır. Söz konusu bezeme anlayışı Sardeis ${ }^{48}$ ve Thyateira ${ }^{49}$ örneklerinde de karşımıza çıkmaktadır. Tís 18.133, TIS 19.SK S-147, TİS 19.SK S-96 ve TİS 19.SK S-55 envanter numaralı parçaların üzerinde ise "damarlı boyama" tekniğinin daha mat bir şekilde uygulandığı anlaşılmaktadır. Daskyleion ${ }^{50}$ ve Börükçü 51 buluntusu "damarlı boyama" örneklerinde de benzer bir bezeme anlayışı vardır.

\footnotetext{
33 Gürtekin-Demir 2002, 122.

34 Gürtekin-Demir 2007, 49.

35 Gürtekin 1998, 242-243.

36 Gürtekin 1998, 243, no. 126, şek. 32, lev. 49.

37 Çakan 2018, 49, kat. no. 32, 168, 172, 267, 268, 269.

38 Çakan 2018, 49, kat. no. 26, 28, 167, 264, 266.

39 Hanfmann et al. 1967, 41, fig. 22; Greenewalt et al. 1990, dn. 19; Gürtekin 1998, 243, no. 125, şek. 32, lev. 49; Greenewalt 2010, 108, no. 78 .

${ }^{40}$ Gürtekin-Demir 2002, 123-127, kat. no. 34-57; Koçak-Yaldır 2009, 96, L44, L107, L120, L121.

${ }^{41}$ Çakan 2018, 49, kat. no. 12, 33.

42 Özver 2012, 11-12, k1-6.

${ }^{43}$ Gider-Büyüközer 2014, 115-116, fig 6-7.

44 Özver 2012, 12, k7.

45 Lydia skphos krater örnekleri için bk. Ramage 1994, 174, lev. 15.4.5; Gürtekin 1998, no. 67, lev. 21; Greenewalt 2010, 110, fig. 10.

46 Çakan 2018, 49, kat. no. 30.

47 Gürtekin-Demir 2014, 228, fig. 10. Gürtekin-Demir söz konusu parçanın Phryg tipi metal taklidi seramikleri hatırlattığını ifade etmektedir.

48 Gürtekin 1998, 242.

49 Akdeniz ve Erön 2017, 88-89, fig. 10-11, çiz. 7-8; Çakan 2018, 49, kat. no. 173.

50 Koçak-Yaldır 2009, L69.

51 Gider-Büyüközer 2014, 115-116, fig 6-7.
} 
TİS 19.SK S-96 envanter numaralı parçanın dışında, rezerve alan içerisinde konsantrik yarım daire bezemelerine yer verildiği anlaşılmaktadır. Konstantrik yarım daire ${ }^{52}$ ve konsantrik kanca dizisi ${ }^{53}$ bezemeleri "kırmızı üzerine siyah" ve "bikrom" tekniklerinde sevilerek kullanılmıştır. Sardeis buluntusu askı konsantrik yarım daire bezemeli seramiklerin üretiminin MÖ 7. yüzyılda başladığı bilinmektedir ${ }^{54}$. TİS 19.SK S-96 numaralı parçanın korunan bölümünden anlaşıldığı kadarıyla, daire sayısının 3 veya 4 olması gerekir. TIS 19.SK S-55 numaralı eserin tutamak bölümünün solundaki alanda ise geometrik desenlerin tercih edildiği anlaşılmaktadır. Fakat söz konusu parça da çok küçük olduğu için bezeme hakkında net bir şey söylemek oldukça zordur.

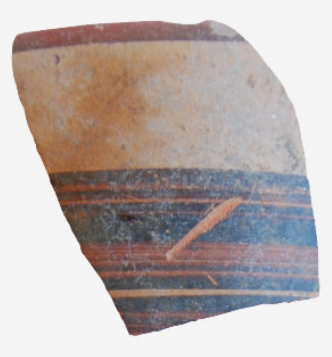

TiS 19.SK S-36

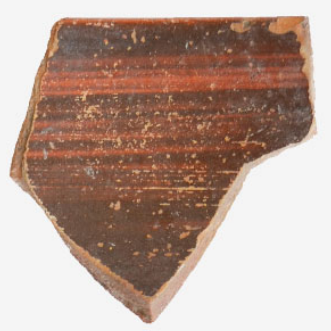

Tis 19.SK S-147

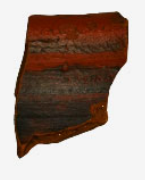

Tis 18.172

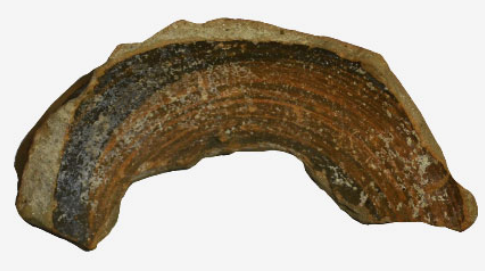

Tis 18.133

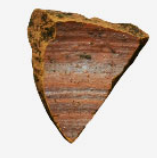

Tis 18.42

Figür 5: Tisna buluntusu "damarlı boyama" seramik örnekleri

"Damarlı boyama" tekniğinin MÖ 8. yüzyılın sonlarından itibaren görülmeye başlandığı bilinmektedir. Tekniğin yoğun kullanımı ise MÖ 7.-6. yüzyıl arasındadır55. Sardeis ${ }^{56}$, Ephesos ${ }^{57}$, Daskyleion ${ }^{58}$, Smyrna ${ }^{59}$, Aphrodisias ${ }^{60}$, Thyateira61 ve Börükçü' de ${ }^{62}$ "damarlı boyama" tekniğinde yapılmış seramik örnekleri bulunmuştur. Yukarıda değinilen merkezlerde bulunan "damarlı boyama" tekniğinde yapılmıs olan seramikler genel olarak MÖ 7.-6. yüzyıllar arasına tarihlendirilmiştir. Tisna buluntusu seramikler de benzer örnekler ve diğer buluntular yardımıyla MÖ Geç 7.-Erken 6. yüzyıla tarihlenebilir.

52 "Kırmızı üzerine siyah" tekniğinde yapılmış örnek için bk. Gürtekin 1998, 40, no. 40, lev.12. "Bikrom" teknikteki örnek için bk. Gürtekin 1988, 134-137, no. 66, lev. 21.

53 Gürtekin 1998, 132-134, no. 65, 67, lev. 21.

54 Gürtekin 1998, 137.

55 Gürtekin-Demir 2002, 123.

56 Greenewalt 1966, 127-128; Gürtekin 1998, 243.

57 Kerschner 2007, 234-235, lev. 33.1.

58 Gürtekin-Demir 2002, 122-123, fig. 11-14; Koçak-Yaldır 2009, 96-97.

${ }^{59}$ Kerschner 2010, 254, fig. 3

60 Mierse 1986, 418.

${ }^{61}$ Akdeniz ve Erön 2017, 88-89, fig. 10-11, çiz. 7-8; Çakan 2018, 49.

62 Gider-Büyüközer 2014, 115-116, fig 6-7. 


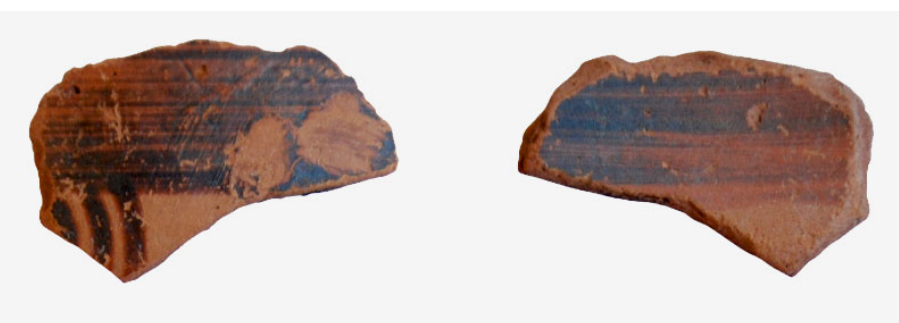

\section{TiS 19.SK S-96}
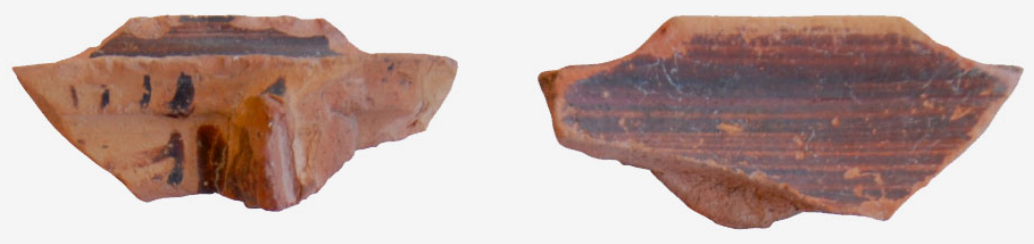

TiS 19.SK S-55

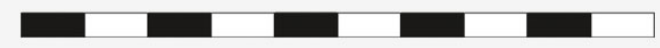

Figür 6: Tisna buluntusu “Damarlı Boyama” seramik örnekleri

\section{Sonuç}

Tisna antik kenti Aiolis Bölgesi'nin doğusunda yer almaktadır. Yerleşimin Lydia Bölgesi' ne bağlanan bir yol ağının yakınında kurulması nedeniyle Lydia kültürü ile etkileşim içerisinde olduğu düşüncesi üzerinde durulmaktadır. Kentte gerçekleştirilen yüzey araştırmaları sırasında bulunan Lydia seramikleri de bu etkiyi kanıtlaması açısından oldukça önemlidir. Çalışma içerisinde 7 tane Lydia seramiği parçası incelenmiştir. Seramik parçalarından 5 tanesi Sarıkale Tepe, 2 tanesi ise Kocakale Tepe mevkiilerinde bulunmuştur. Sarıkale Tepe mevkii buluntularının çok önemli bir bölümü kutsal alan olduğu düşünülen bir arazide tespit edilmiştir. Yapılan incelemeler sonucunda seramiklerin tamaminın "damarlı boyama" tekniğinde yapıldığı anlaşılmaktadır. "Damarlı boyama" tekniği Lydia seramiklerinin en karakteristik bezeme üsluplarından bir tanesi olarak karşımıza çıkmaktadır.

Lydia Krallı̆̆ı'nın özellikle MÖ 7.-6. yüzyıllar arasında Batı Anadolu coğrafyası üzerinde hakimiyet kurduğu bilinmektedir. Lydia seramikleri de söz konusu dönemde geniş bir coğrafyada karşımıza çıkar. Aiolis Bölgesi'nin doğusunda yer alan Tisna'da da Lydia seramiklerinin bulunması oldukça önemlidir. Tisna her ne kadar Aiolis Bölgesi sınırları içerisinde değerlendirilse de konum itibariyle Lydia kültürüyle etkileşime açıktır. Yerleşimin hemen yanından geçen bir yol ile Lydia Bölgesi'ne bağlandığı bilinmektedir. Tisna antik kentinde gerçekleştirilen yüzey araştırmaları sırasında Sarıkale Tepe mevkiinin güney yamacında büyük bir nekropolis alanı saptanmıştır. Büyük oranda tahrip edilmiş mezarların içerisinde genel olarak MÖ 7.-6. yüzyıllar arasına tarihlendirilen seramik parçaları bulunmuştur. Nekropolis kalıntı ve buluntuları Sarıkale Tepe mevkinin MÖ 7.-6. yüzyıllar arasında iskan gördüğünü kanitlar niteliktedir63. Çalışma içerisinde incelenen Lydia "damarlı boyama" tekniğinde yapılmış seramik örnekleri benzer örnekler ve yerleşimdeki diğer buluntular yardımıyla MÖ Geç 7.-Erken 6. yüzyıllar arasına tarihlendirilmiştir.

63 Erdan ve Aydoğmuş 2019, 1140-1141. 


\section{Katalog}

Envanter No: TİS 18.42

Buluntu Yeri: Kocakale Tepe, Kuzey, Kaya Mezarı 2 Çevresi

Formu: Tabak (?)

Hamur/Astar/Katkı: Hamur: 7.5 YR 7/4 pembe hamur. İç: 2.5 YR 4/2 soluk kırmızı. Dış:7.5 YR 6/ 4 açık kahverengi ve 7.5 YR 2.5/1 siyah. Mika katkılıdır.

Ölçüleri: Y. $2.8 \mathrm{~cm} ;$ G. $2.4 \mathrm{~cm}$.

Tanımı: Gövde parçasıdır. Dış yüzeyde, korunan gövdenin üzerinde rezerve alanın üzerinde kırmızımsı kahverengi firnis bant, iç yüzeyde ise kırmızı firnis üzerine koyu kahverengi firnis bantlar görülmektedir.

Boyama Tekniği: Damarlı boyama

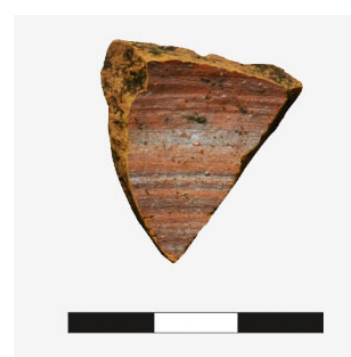

Tis 18.42

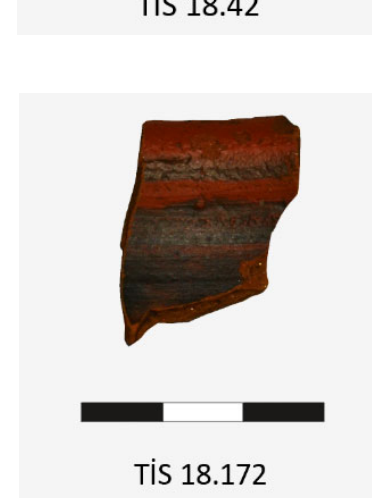

Tis 18.172

Envanter No: TİS 18.172

Buluntu Yeri: Kocakale Tepe, Kuzey, Kaya Mezarı 2 Çevresi

Formu: (?)

Hamur/Astar/Katk1: 7.5 YR 6/4 açık kahverengi. İç: 7.5 YR 2.5/1 siyah, 2.5 YR 4/8 kırmızı. Dış: 10 YR 7/4 çok soluk kahverengi ve 10 YR 4/1 çok koyu gri. Kum ve mika katkılıdır.

Ölçüleri: Y. $1.8 \mathrm{~cm}$; G. $2.1 \mathrm{~cm}$, Ç. $8 \mathrm{~cm}$.

Tanımı: Ağız parçasıdır. İç yüzeyinin tamamı ve dış yüzeyinin dudak ve dudak altı kısmında açık kırmızı üzerine siyah firnis bulunmaktadır.

Boyama Tekniği: Damarlı boyama

Envanter No: TİS 18.133

Buluntu Yeri: Sarkkale Tepe, Akropol

Formu: Oinokhoe

Hamur/Astar/Katkı: Hamur: 7.5 YR 5/4 kahverengi. İç astar: 7.5 YR 3/1 çok koyu gri ve 7.5 YR 4/3 kahverengi. Diş firnis bant: 10 YR 4/2 koyu grimsi kahverengi. Kireç, mika katkılıdır.

Ölçüleri: Y. $2.5 \mathrm{~cm}$; Ç. $9 \mathrm{~cm}$.

Tanımı: Kaide parçasıdır. Dış yüzeyinde gövdeden kaideye geçişte kalın bir yiv üzerinde kahverengimsi firnis bant vardır. İç yüzeyde ise kırmızı astar üzerinde koyu kahverengimsi biri kalın diğerleri ince olan firnis bantlar görülmektedir.

Boyama Tekniği: Damarlı boyama
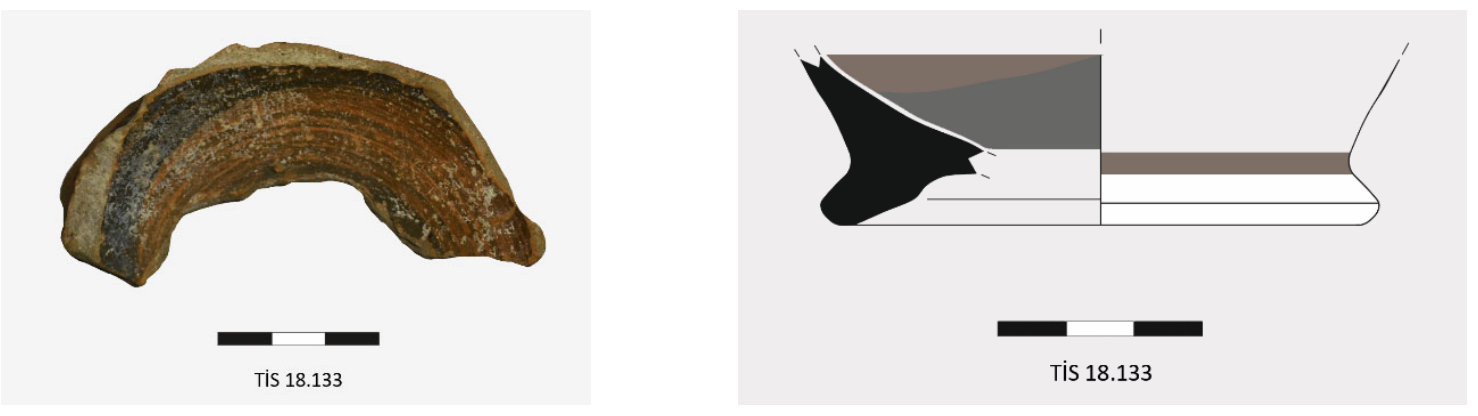

Envanter No: TİS 19 SK S-36

Buluntu Yeri: Sarıkale Tepe Kutsal Alan

Formu: Skyphos

Hamur/Astar/Katkı: Hamur 5 YR 7/4 pembe. Dış: 7.5 YR 6/4 açık kahverengi astar (ağı formundan gövdeye doğru), firnis bantlar:10 R 4/4 soluk kırmızı, 10 R 3/1 koyu kırmızımsı gri, 2.5 YR 4/6 kırmızı. İç: 2.5 YR 2.5/1 kırmızımsı siyah astar. Az miktarda kum ve mika.

Ölçüleri: Y. $5 \mathrm{~cm}$; Ç. $12 \mathrm{~cm}$.

Tanımı: Ağız parçasıdır. Eser ağız oturma düzleminden içe doğru içbükey yaparak inmektedir. Dış yüzeyin dudak kısmında $0.5 \mathrm{~cm}$ genişliğinde soluk kırmızı bir bant, $2.2 \mathrm{~cm}$ yüksekliğinde rezerve bir alan ve ardından koyu kırmızımsı gri ve kırmızı renk geçişlerine sahip farklı yüksekliklerde bant sırası yer almaktadır. İç yüzey üzerinde siyah astar görülmektedir.

Boyama Tekniği: Damarlı boyama 

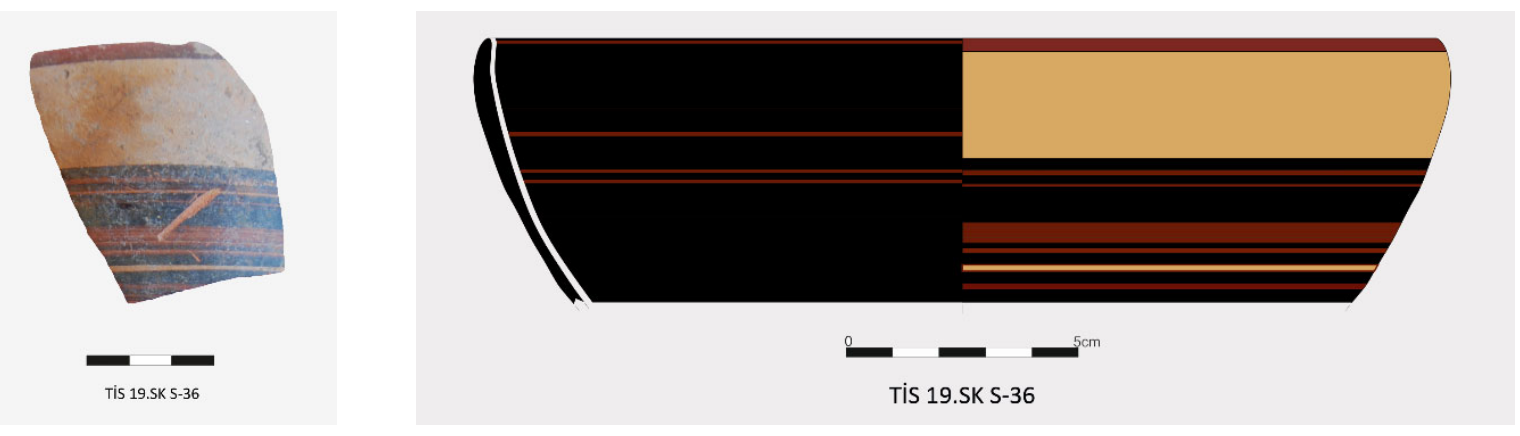

Envanter No: TİS 19 SK S-147

Buluntu Yeri: Sarıkale Tepe Batı Yamacı

Formu: Tabak

Hamur/Astar/Katkı: Hamur: 5 YR 6/6 kırmızımsı sarı. Dış: 2.5 Y _/2/8 Soluk sarı astar. 2.5 YR 5/6 kırmızı boya. 5 YR 3/1 koyu kırmızımsı gri boya İç: 5 YR 3/3 koyu kırmızımsı kahverengi boya, 2.5 YR 3/6 koyu kırmızı boya. Kum, kireç katkılıdır.

Ölçüleri: Y. $3.6 \mathrm{~cm}$; Ç. $12 \mathrm{~cm}$.

Tanımı: A ğı parçasıdır. Ağız oturma düzlemi üzerinde kırmızı boya ile bir bezeme alanı oluşturulup koyu kırmızımsı gri boya ile ince bir bant bezemesine yer verilmiştir. Dış yüzeyde ağız oturma düzleminin hemen altında soluk sarı astar üzerine kırmızı boya ile ince bantlar yapılmıştır. Dış yüzeyde gövde üzerinde kırmızı ve koyu kırmızı gri boya ile bezeme alanları oluşturulmuştur. İç yüzeyde koyu kırmızımsı kahverengi boya üzerine koyu kırmızı boya ile çizgisel bezeme yapılmıştır.

Boyama Tekniği: Damarlı boyama
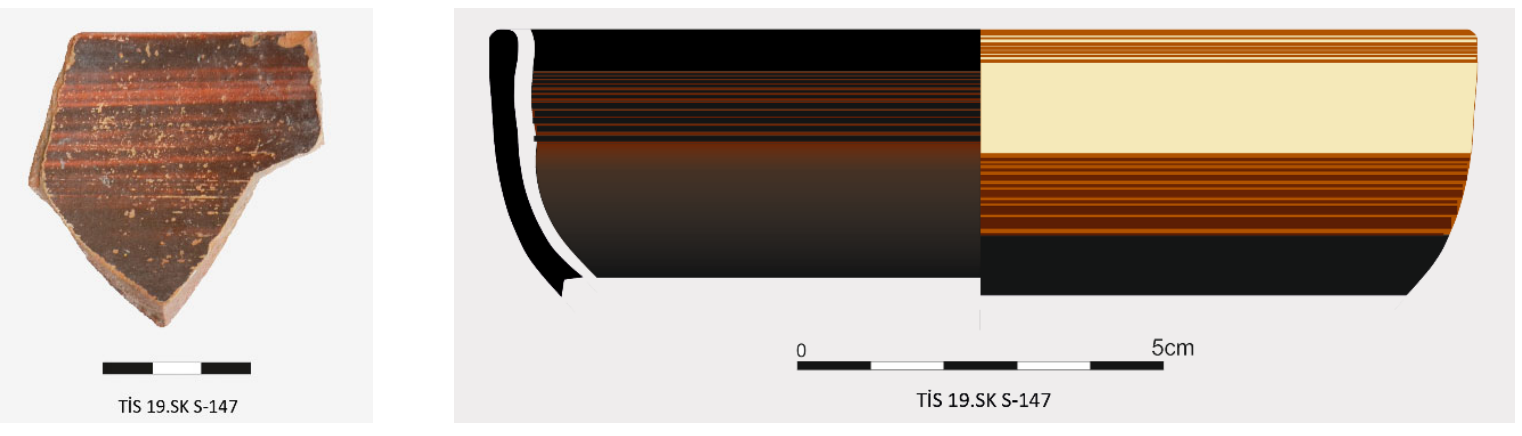

Envanter No: TİS 19 SK S-55

Buluntu Yeri: Sarıkale Tepe Kutsal Alanın Güneyindeki Tepe

Formu: Çanak

Hamur/Astar/Katkı: Hamur: 10R 7/4 soluk kırmızı, Dış: 2.5 YR 2.5/1 kırmızımsı siyah (tutamak tablası), 2.5 YR 2.5/1 kırmızımsı siyah (motif), İç: 2.5 YR 3/2 siyahımsı kırmızı. Kireç, taşçık ve az miktarda da kum katkılıdır.

Ölçüleri: Y. $3.5 \mathrm{~cm}$; A ğız G. $3.8 \mathrm{~cm}$.

Tanımı: Ağız parçasıdır. $3.5 \mathrm{~cm}$ genişliğinde korunan ağız parçasının dış yüzeyde hemen altında gövdeden 1.1 cm ölçüsünde dışarıya düz bir şekilde profil veren olasılıkla bir kapak tablası bulunmaktadır. Söz konusu alanın hemen altında küçük bir tutamak yer alır. Dış yüzeyde ağızdan kapak tablasının bitimine kadar kırmızımsı siyah renginde firnis bulunmaktadır. Gövdeye geçiş 0.9 cm'lik keskin bir dönüş ile bağlanır ve üzerinde kırmızımsı siyah renginde aşınmış kısa çizgisel motifler görülür. Tutamak yerinin sol alanında da kırmızımsı siyah renginde oldukça az korunmuş bir bezeme alanı mevuttur. İç yüzey 0.5 cm'lik bir ağız kalınlığından konkav şekilde içe doğru uzanir.

Boyama Tekniği: Damarlı boyama

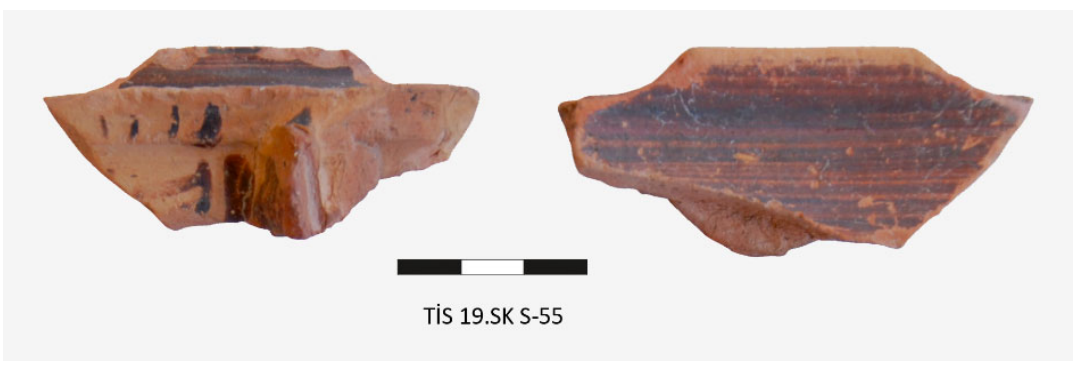




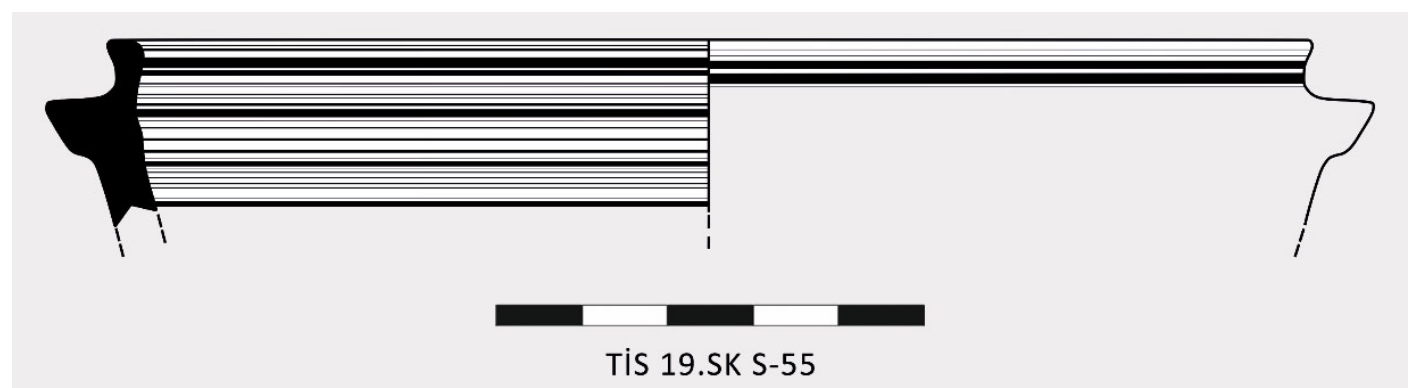

Envanter No: TİS 19 SK S-96

Buluntu Yeri: Sarıkale Tepe Kutsal Alan Batı Yamacı

Formu: Skyphos krater

Hamur/Astar/Katkı: Hamur: 5 YR 6/4 acık kırmızımsı kahverengi Dış: 7.5 YR 7/4 pembe astar üzerine 7.5 YR 2.5/1 siyah İç: 7.5 YR 2.5/1 siyah ve 2.5 YR 5/6 kırmızı astarlıdır.

Ölçüleri: Y. $2.8 \mathrm{~cm}$; G. $4.3 \mathrm{~cm}$; K. $0.5 \mathrm{~cm}$.

Tanımı: Gövde parçasının dış yüzeyinde pembe astar üzerine siyah firnis ile $1.6 \mathrm{~cm}$ yüksekliğinde bir bant yer almaktadır. Bu alanın hemen altında yan yana üç sıra halinde fırça ile yapılmış $0.3 \mathrm{~cm}$ kalınlığında çizgisel bezeme yer almaktadır. İç yüzeyde pişirmeden kaynaklı olarak renk geçişleri görülmektedir.

Boyama Tekniği: Damarlı boyama

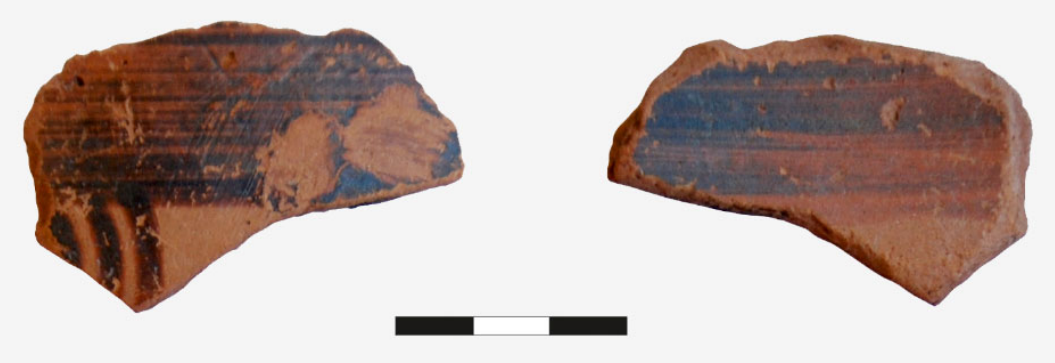

Tis 19.SK S-96

\section{Figürlerin Listesi}

Figür 1: Tisna antik kenti ve yakın çevresini gösteren harita

Figür 2: Sarıkale Tepe akropolü ve batı yamacının genel görünüşü

Figür 3: Kocakale Tepe mevkiinin genel görünüşü

Figür 4: Tisna buluntusu "Damarlı Boyama" seramiklerinin buluntu yerlerini gösteren harita

Figür 5: Tisna buluntusu "damarlı boyama" seramik örnekleri

Figür 6: Tisna buluntusu "damarlı boyama” seramik örnekleri 


\section{Bibliyografya}

Akdeniz, E. ve Erön, A. (2017). Lydia Kültürünün Kuzey Lydia'daki İzleri: ThyateiraHastane Höyüğü Kazıları'nda Bulunan Lydia Seramikleri. Tüba-Ar, 20, 79-92.

Akurgal, E. (1950). Bayraklı Kazısı Ön Rapor. Ankara Üniversitesi Dil ve Tarih-Coğrafya Fakültesi Dergisi, VIII(1-2), 1-51.

Boehlau, J. ve Schefold, K. (1942). Larisa am Hermos: die Ergebnisse der Ausgrabungen, 19021934. Band III, Die Kleinfunde. Berlin: Walter de Gruyter.

Brein, F. (1978). Geometrisch Dekorierte Keramik aus Ephesos. E. Akurgal (Ed.), The Proceedings of the Xth International Congress of Classical Archaeology (ss. 721-728). Ankara: Türk Tarih Kurumu.

Conze, A. (1910). Eine Griechische Stadt. JdI, 25, 1-8.

Cook, J. M. (1958/1959). Old Smyrna, 1948-1951. BSA, 53/54, 1-34.

Çakan, M. S. (2018). Hastane Höyüğ̈̈̈ Kazılarında Ele Geçen Lydia Seramikleri Işı̆̆ında M.Ö. 8-6. Yüzyıllar Arasında Thyateira Antik Kenti [Yayınlanmamış Yüksek Lisans Tezi]. Aydın Adnan Menderes Üniversitesi, Aydın.

Doğer, E. (2017). Aliağa Tarihi: İlk Çă̆g'dan 21. Yüzyıla, Ankara: Aliağa Kent Kitaplığı.

Erdan, E. (2019). Tisna Antik Kenti. M. Çekilmez (Ed.), Aliağa ve Çevresindeki Antik Kentler (ss. 91-111). Ankara: Aliağa Kent Kitaplığı.

Erdan, E. ve Aydoğmuş, N. (2019). Aiolis'te Yeni Bir Arkaik Dönem Nekropolü Hakkında İlk Gözlemler: Tisna-Sarıkale Tepe Güney Yamacı. Atatürk Üniversitesi Sosyal Bilimler Enstitüsü Dergisi, 23(3), 1131-1157.

Erdan, E., Çekilmez, M., Tiro, A. O., Aydoğmuş, N., Yılmaz-Karabulut, N., Vardar, S., Gür, B., Semiz, B., Kapuci, U., Arınç, M., Ersavaş, K., Taşpınar, P., Yüksektepe, Y. B., ve Toprak, G. T. (2019). Tisna Antik Kenti ve Yakın Çevresi Yüzey Araştırması 2018 Yı1ı Çalışmaları. Araştırma Sonuçları Toplantısı, 37(1), 459-470.

Erdan, E. (2020a). Tisna I: İlk Araştırmalar ve Gözlemler. İstanbul: Ege Yayınları.

Erdan, E. (2020b). Tisna and the First Results of the New Researches. M. Çekilmez (Ed.), Aliağa ve Çevresi, Uluslararası Aliağa ve Çevresi-Aiolis Bölgesi-Arkeoloji ve Disiplinler Arası Araştırmalar Sempozyumu Bildirileri (ss. 353-371). İzmir.

Gider-Büyüközer, Z. (2014). Börükçü Nekropol Alanından Bir Arkaik Mezar. Tüba-Ar, 17, 111-128.

Greenewalt, C. H. (1966). Lydian Pottery of the Sixth Century B.C.: The Lydion and Marbled Ware [Yayınlanmamış Doktora Tezi]. Pennsylvania Üniversitesi, Pennsylvania.

Greenewalt, C. H. (2010). Lidya'da Çömlekçilik/Lydian Pottery. N. D. Cahill (Ed.), Lidyalılar ve Dünyalarl/The Lydians and Their World (ss. 107-124). İstanbul: Yapı Kredi Yayınları.

Greenewalt C. H., Cahill, N. D., Dedeoğlu, H. ve Hermann, H. (1990). The Sardis Campaign of 1986. BASOR Supplementary Studies, No. 26, 137-177. 
Gürtekin, R. G. (1998). Lydia Seramiğindeki Yabancı Etkiler [Yayınlanmamış Doktora Tezi]. Ege Üniversitesi, İzmir.

Gürtekin-Demir, R. G. (2002). Lydian Painted Pottery at Daskyleion. AnatSt, 52, 111-143.

Gürtekin-Demir, R. G. (2007). Provincial Production of Lydian Painted Pottery. A. Sagona ve A. Çilingiroğlu (Eds.), Anatolian Iron Ages 6: The Proceedings of the Sixth Anatolian Iron Ages Colloquium Held at Eskişehir (16-20 August 2004), Ancient Near Eastern Studies Supplement 20 (ss. 47-77). Louvain.

Gürtekin-Demir, R. G. (2011). An Eastern Mediterranean Painting Convention in Western Anatolia: Lydian Black-on-Red. K. Duistermaat ve I. Regulski (Eds.), Intercultural Contacts in the Ancient Mediterranean, Proceedings of the International Conference at the Netherlands-Flemish Institute in Cairo, 25-29 October 2008 (ss. 359-378). Paris: Peeters.

Gürtekin-Demir, R. G. (2014). Phrygian Aspects of Lydian Painted Pottery. AJA, 118(2), 223239.

Hanfmann, M. A., Swift, G. F. ve Greenewalt, C. H. (1967). The Ninth Campaign at Sardis (1966). BASOR, 186, 17-52.

Kerschner, M. (2007). Das Keramikbild von Ephesos im 7. und 6. Jh. v. Chr. J. Cobet, V. von Graeve, W. D. Niemier ve K. Zimmermann (Eds.), Frühes Ionien Eine Bestandsaufnahme, Milesische Forschungen 5 (ss. 221-245). Mainz am Rhein: Philipp von Zabern.

Kerschner, M. (2008). Artemis Kutsal Alanı'nda Bulunan Pişmiş Toprak Kaplar. W. Seipel (Ed.), Efes Artemisionu. Bir Tanrıçanın kutsal mekânı (ss. 331-345). Viyana: Phoibos Verlag.

Kerschner, M. (2010). Lidyalıların Komşuları İyonyalılar ve Aiolia'lılar. N. D. Cahill (Ed.), Lidyalılar ve Dünyalar/The Lydians and Their World (ss. 247-266). İstanbul: Yap1 Kredi Yayınları.

Kızıltepe-Bilgin, P. (2018). Afyonkarahisar İli Yüzey Araştırmaları Işı̆̆ında İçbatı Anadolu'da Demir Çă̆ı Seramiği [Yayınlanmamış Yüksek Lisans Tezi]. Pamukkale Üniversitesi, Denizli.

Koçak-Yaldır, A. (2009). İ.Ö. Yedinci ve Altıncı Yüzyıllarda Daskyleion'un Ticari İlişkileri [Yayınlanmamış Doktora Tezi]. Ege Üniversitesi, İzmir.

Mellaart, J. (1955). Iron Age Pottery From Southern Anatolia. Belleten, XIX(74), 115-136.

Mierse, W. E. (1986). Lydian Pottery at Aphrodosias. M. S. Joukowsky (Ed.), Prehistoric Aphrodisias Volume 2. An Account of the Excavations and Artifact Studies (ss. 413-424). Louvain: Brown University.

Özver, A. (2012). Aigai'den Ele Geçen Arkaik Dönem Seramikleri [Yayınlanmamış Yüksek Lisans Tezi]. Ege Üniversitesi, İzmir.

Panteleon, I. A. ve Senff, R. (2008). Die Grabung im Aphroditeheiligtum auf dem Zeytintepe bei Milet in den Jahren 2003-2005. AA, 2008(2), 33-46.

Ramage, N. H. (1994). Pactolus Cliff: an Iron Age site at Sardis and its pottery. A. Çilingiroğlu ve D. H. French (Eds.), Anatolian Iron Ages 3/Anadolu Demir Çağlarn 3, The Proceedingd of the Third Anatolian Iron Ages Colloquium held at Van, 6-12 August 1990/III. 
Anadolu Demir Çă̆lan Sempozyumu Bildirileri Van, 6-12 Ağustos 1990 (ss. 173-183). Ankara: British Institute of Archaeology at Ankara.

Reinach, S. (1885). Chronique d'Orient. RA Troisième Série T. 5, 69-98.

Reinach, S. (1891). Chroniques d'Orient: documents sur les fouilles et découvertes dans l'Orient hellénique de 1883 à 1890. Paris: F. Didot frères.

Sams, G. K. (1979). Imports at Gordion. Lydian and Persian Periods. Expedition, 21(4), 6-17.

Sayce, A. H. (1882). Explorations in Aeolis. JHS, 3, 218-227.

Schaus, G. P. (1992). Imported West Anatolian Pottery at Gordion. AnatSt, 42, 151-177.

Schuchhardt, C. (1887). Vorläufiger Bericht über eine Bereisung der pergamenischen Landschaft. Sitzungsberichte der Königlich Preussischen Akademie der Wissenschaften zu Berlin, $1887,1207-1214$.

von Diest, W. (1889). Pergamon über den Dindymos zum Pontus, Gotha: Justus Perthes. 